\title{
DESIGN THINKING AS A TOOL FOR PARTICIPATORY AND TRANSFORMATIVE TRANSLATOR EDUCATION
}

\author{
KONRAD KLIMKOWSKI \\ John Paul II Catholic University of Lublin, Poland \\ konrad.klimkowski@kul.pl \\ KATARZYNA KLIMKOWSKA \\ Maria Curie-Skłodowska University in Lublin, Poland \\ katarzyna.klimkowska@mail.umcs.pl
}

\begin{abstract}
This article outlines the main tenets and the working cycle of Design Thinking, which is a problem-solving methodology. We argue that this methodology helps train qualities and skills that are particularly beneficial for students of translator education programmes. We recommend Design Thinking for translation teachers who subscribe to post-positivist, constructivist and other problem-based, participatory and collaborative educational approaches. The latter part of the article presents examples of classroom activities developed with the use of Design Thinking methodology. The activities focus mostly on communicative interactions between participants, since we believe that the major advantage of Design Thinking for the translation classroom is that it offers a structured scaffolding to improve classroom communication.
\end{abstract}

Keywords: Design Thinking, translator education, educational approach, classroom activity, classroom communication, project method, problem-based learning

\section{Introduction}

The past two decades witnessed a tremendous change in academic translator education. From autotelic programmes in an ivory tower regime, academic translation courses are globally evolving into dynamic learning environments. A growing number of translator educators launch real-life translation projects (e.g. Fernández Sánchez 2008, Kiraly 2016, Klimkowski 2015, Massey and Brändli 2016 or Pitkäsalo and Ketola 2018), or even start up translation agencies where translation students can perform in a business context (e.g. skills lab discussed e.g. by Thelen 2019).

Notwithstanding the numerous advantages of the change, one can also point out challenges that it evokes. Making learning more dynamic, real-life (situated) and pragmatically oriented poses challenges for all the stakeholders. Students grow to realize a transition period in their life, and the change they are in for is 
not always what they want. Teachers find themselves in a constant need to relearn how to teach. A project laboriously developed for two or three years may no longer provide a valid learning context in the years to follow. Universities more readily address their responsibility for the world outside their walls, but this can also lead to their reorganization - a process that entails risks to the academia. Finally, the translation industry has a lesson to learn on how to work with new market members and help graduates determine their career trajectories.

This article mainly adopts the point of view of the translation teacher and a need to re-envision the educational scaffolding they provide. The article contains a recommendation of Design Thinking as a methodology that can enrich the repertoire of a contemporary translator teacher. Design Thinking is a relatively recent problem-solving methodology that occurred in the field of design, yet is extensively used in educational contexts like training and mentoring. In brief, Design Thinking invites decision makers (designers, students, teachers, etc.) to take a problem to be solved out of the confines of the existing solutions. To do that, Design Thinking recommends a deeper insight into the problem to disclose its real background. Design Thinking is not about finding the fastest route to a solution. It addresses human needs that manifest themselves through the problem. Design Thinking relies on and helps master creativity (play), teamwork, focus (insight), goal-oriented performance and process ownership (accountability).

The article presents the main tenets of Design Thinking that are of significance in the translator education context. It also outlines a full methodological cycle of a Design Thinking workshop. ${ }^{1}$ Since this educational methodology rests on specific - yet not necessarily overt - epistemological assumptions, we devote some space to discuss these. We want to make it clear to the reader that prior to enlisting Design Thinking in their methodological repertoire, they need to make other choices for the method to be effective and satisfying. The article ends with two suggested didactic activities that employ basic ideas from Design Thinking.

\section{Design Thinking: main tenets}

Providing one exhaustive definition of Design Thinking is a troublesome task since diverse adherents in different fields of human activity tend to give the concept its idiosyncratic reading. The most basic claim made by its proponents is that Design Thinking is a problem-solving method (Brown 2009). In fact, there is more than one method involved in the Design Thinking cycle, hence it seems reasonable to refer to it as methodology.

Innovation and creativity are defining features for Design Thinking. These two qualities are understood as ability to expand the field of perception of the people engaged in problem-solving, so as to reach beyond even the most complex

1 The workshop we present is authored by Google. See References for detail. 
combinations of solutions available to them so far. Hence, Design Thinking can equally result in new solutions and in redefining the problem itself. As observed by Tim Brown - recognized as a founding father of Design Thinking ${ }^{2}-$ this methodology is intended to challenge one of the serious myths of our society that:

brilliant ideas leap fully formed from the minds of geniuses. The reality is that most innovations come from a process of rigorous examination through which great ideas are identified and developed before being realized as new offerings and capabilities." (Brown, 2009, book cover).

Thus, innovation does not have to be revolutionary or disruptive in its scale and perceived intensity. Design Thinking wants to be innovative by seeking what particular human needs can be satisfied by a designed solution. To do so, Design Thinking focuses on expanding the insight into the human side of the problem to be solved. Consequently, the solutions developed are an outcome of "collaborative process by which the designer's sensibilities and methods are employed to match people's needs" (Brown 2009, book cover).

Another key assumption of the method is its transformative effect: the kind of innovation introduced by Design Thinking in a workplace, project or learning environment does not only solve a particular problem, but it significantly changes the workplace (project team, classroom etc.). Solving the original problem in an innovative way can unveil needs and methods of redesigning an organization or a learning environment as a precondition for the innovative solution to be fully implemented.

Taking the above into consideration, one can understand why Design Thinking is also conceived of in terms of attitude or mindset, which is particularly underlined by the notion of "Thinking" in its name. Under this take, Design Thinking is depicted as a problem-solving methodology with a transformative, lasting effect.

The notion of transformation - even if used in an organizational context always concerns humans: mindsets, attitudes, norms and actions. Proponents of Design Thinking underlie its being human-centred, and this claim can be supported by a few observations about Design Thinking and its assumptions apart from the transformational impact discussed above. Firstly, even though the direct reason for implementing Design Thinking is to solve a problem, in fact the methodology assumes efforts to shed light onto human needs, whose satisfaction is thwarted by the problem. Secondly, Design Thinking is a process of problemsolving where design competences are shared by designers with those who experience problems. Thirdly, Design Thinking methodology relies on teamwork: all the stages in the Design Thinking cycle include a mixture of individual and team creative effort.

2 For other advocates and promoters of Design Thinking, see the DESIGN THINKING Workshop by Google we draw upon in this article. See References for detail. 
Last but not least, Design Thinking is product-oriented and effect-driven. This is usually the case with methodologies that come into operation in a business context. Business organizations value mainly those philosophies of change that can promise them real and tangible results. Thus, the designed solutions must be prototyped and tested for their effective handling of a problem.

\section{Design Thinking at play}

This section outlines the stages of the Design Thinking process to give the reader a more process-oriented outlook of the method. ${ }^{3}$ The first stage is diagnosis, and it serves to determine the real nature of the problem to be solved. It must also be noted that apart from classically understood problem solving, Design Thinking is also useful in defining new (business) opportunities that can help an organization or a team to make a market leap.

To illustrate that stage let us present a short description of a potential problem:

"A" is a translator who considers a marketing strategy having to make choices between: (a) dedicated website, (b) an embedded website at a social media platform, (c) no website, only social media activity and portfolio display, (d) a document-based portfolio and other marketing content disseminated on demand

The second stage of the process expands the diagnosis through interviews with people who experience a problem. The aim of the designer is to listen to and for their needs in a broader context than that of the particular crisis. This kind of listening is full of empathy and readiness to hear the people's story behind the problem: values, needs, desired future (when the problem is no longer there). The aim of this stage is creating a portrait of the person who is the main protagonist in the context of the problem. To discern the full complexity of the subject matter the designer needs to consider the affective, relational (interpersonal) and organizational (teamwork, project) consequences and conditioning of the problem.

As a way of illustration, consider the following two statements related to the problem discussed above:

\section{This translator needs clients and keep marketing cost low}

2. This translator needs a marketing strategy to find clients

These statements can by and large be true and pertinent to the situation, yet they express what a designer thinks about the situation. His/her judgment leads to "handy" solutions that seem evident and practicable. However, the designer fails to explore a broader view of the needs and motives of this particular translator in

3 All the stages are an abbreviated and simplified version of the guidelines for DESIGN THINKING workshop by Google. See References for detail. 
his/her service context - of which we know nothing without asking questions. Thus, a post-interview diagnosis of the problem could rather look like to the following:

A is a translator who wishes to enter the market after her "maternity leave" period. She has a part-time job and translation - even though directly related - is to account for up to 30 percent of her annual income. Her business strategy is focused on repeat, direct customers in the field $\mathrm{B}$ and $\mathrm{C}$ and her portfolio includes translation, transcreation, interpreting and specialist language training...

This interview script draws a more complex map of the translator's needs and problems (choices). We learn about the particular employment status of the interviewee, her financial expectations, client management policy and specialization domains.

Having at hand a broad map of the problem, we move to stage three, titled problem framing. Its main objective is to translate the situational map from stages one and two on possible strategies to address the problem. Particularly useful at this stage is the modal question "How might we....", which is the main translation tool. The largest challenge at this stage is to scale the designed pathways so that they are neither too general, nor too narrow. In reference to our example case we could imagine the following three options:

\section{How might we find balance between life and work?}

This option that is hard to operationalize on the basis of available information and is an example of a framing that is too general.

\section{How might we establish a number of customers to serve per month?}

This statement is perhaps too narrow in that it only concentrates on one aspect of the problem, saying nothing about the marketing strategy our imagined translator "A" is seeking.

\section{How might we work out a marketing strategy to attract those clients that match my} portfolio?

This statement matches the broad context of the interviewee needs, but it does not have to be the only or the correct framing of her case. Let us also remind the reader that the "How might we..." technique does not yield solutions but insights.

As one can observe, the options that are too broad are hard to operationalize. They are like mottos or sometimes are at the verge of wishful thinking. Framings can also be too narrow, which usually results from our tendency to move as quickly as possible to the concluding stage of design - a solution. Unfortunately, this latter path often focuses more on the designer's idea of the problem and the "appropriate" solution. Thus, covertly, the person experiencing the problem cannot develop his/her ownership of the solution. 
Stage four is devoted to generating a maximum number of options that match the specification established through framing. This is where the group or teamwork comes with help in a method known as brainstorming. Since this method is well-known, we do not discuss it in further detail. The ideas generated in brainstorming are then sieved with an established set of criteria (e.g. voting by team members or pros-cons analysis) to finally arrive at a handful of planned solutions that are subject to stage five, called rapid prototyping.

Rapid prototyping is a technique of checking out the feasibility of a given solution at the earliest possible stage, to reduce energy and financial loss in case a prototyped solution proves to be fiasco. If a prototype passes this stage successfully, a testing phase begins. Even though these two last stages are crucial to the Design Thinking cycle, they are perhaps less instrumental for educational application, and hence we exempt ourselves from discussing them in further detail. This detail is outlined and explored in the sources listed in the References.

\section{Design Thinking in didactic application}

We hope to have shown how Design Thinking exploits creative problem solving and hugely relies on shared agency (collaboration for empowerment). We argue that these qualities can be advantageous in diverse educational contexts. Translator education can particularly benefit from Design Thinking since the three abovementioned qualities are on the list of the desired skills and attitudes of a professional translator (cf. the notion of translation competence). In this article, we focus mostly on the three key features of Design Thinking as instrumental in training a variety of skills and attitudes in the field of Translation Service Provision competence postulated by EMT experts (EMT 2009, 2017).

It is worth noting that the benefits of applying Design Thinking in the translation classroom are most evident for educational approaches that rely on notions of significant (problem-based and task-based) learning, where students are encouraged to become accountable owners of their learning (voices, roles, cf. e.g. González-Davies 2004; Klimkowski 2015, 2019b) and participate in collaborative construction of senses (Kiraly 2000 and later). The translation classroom becomes thus a developmental space shared by two kinds of learners: students and teachers, both pursuing their own developmental trajectories.

In this article, we would like to particularly highlight how Design Thinking can help improve classroom communication. Learning to provide a precise, yet contextualized (holistic) diagnosis of the analysed problem (maps) is a skill often reported as missing in university graduates (Mourshed et al. 2012, 2014, OECD 2019). Asking appropriate questions and attentively obtaining informative responses is a marker of a developing communicative competence. Our reason for highlighting classroom communication - apart from its obvious merit for cognitive and social development - is that communication skills need constant 
deliberate practice, both on the part of students and teachers. A mere decision to take up project work or other problem-based learning methods in the translation classroom does not per se equip the teacher or the students with communication skills necessary for effective functioning in a learning environment based on agency and accountability rather than on obligation. We argue that strategic classroom communication is fundamental for the success of an educational scaffolding which sets itself a lifelong rather than instructionist horizon (cf. e.g. Klimkowska and Klimkowski 2015, Klimkowski 2019a).

\section{Classroom activities}

As can already be evident to the reader, our approach to Design Thinking is selective. We believe that some of its stages like rapid prototyping or testing can rather be problematic for a translation teacher to employ. Still, aspects of this methodology can be utilized to an extent that a teacher finds educationally attractive. A case used as example in the section above can serve as a potential scenario for a team of students working on their career prospects (a dedicated class or workshop). Below, we provide another three scenarios that can be subject to a Design Thinking-based diagnosis, insight and brainstorming session.

\section{Scenario 1: Handling aggressive criticism}

\section{AGENDA:}

1. The activity moderator (e.g. teacher) chooses one student to perform as John/Anne - the translator. The other students perform as solution designers. They cannot modify the main "problem-story".

2. The moderator introduces a problem (story) to the student performing as John/Anne. The student can modify and add to the story. They can also consult (skilfully) the moderator on some details. It can be helpful if the student presents the outline of his story to the moderator before the activity is implemented.

Problem communicated by the activity moderator to John/Anne: You were approached by a client in a verbal aggressive message questioning the quality of your job. The client said that his colleague questioned your translation solutions. You asked him to be more specific and were able to prove your solutions were OK. You want to work with this client in the future: except for this incident, you find your cooperation satisfying in all aspects.

Problem as reported by John/Anne to the group: I was approached by a client in a verbal aggressive message questioning the quality of his translation on the basis of the client's colleague's "expertise".

3. Interview (example questions:) 
- Do we know what happened on the basis of information provided by John/Ann?

- What kind of information is needed to have a broader picture of the case?

- What is the "problem" that John/Ann has? What are/can be its consequences?

4. Framing (example questions:)

- What would John/Ann (you) like to do when faced with this situation?

- How to "design" a response to the client?

- Can something be done to prevent incidents like these in the future?

\section{Brainstorming}

Depending on a number of participants brainstorming may require dividing people into groups. Group selection may be random or may rely on purposeful criteria. For instance, in the case concerning marketing strategy discussed above, groups may be established according to whether participants wish to explore solutions based on a dedicated webpage $\mathrm{v}$. those seeking solutions alternative to web-based marketing.

\section{Feedback}

We strongly recommend that each activity ends with a feedback session, when each participant is given a voice on what happened. Feedback is a moment when each participant has a chance to reflect upon their role performance and share it with the others. This deepens insight into the scenario situation, but - more importantly - helps build reflectivity concerning one's own beliefs and practices (real and declared).

\section{Scenario 2: Briefing}

\section{AGENDA:}

1. The agenda for this scenario can be similar to the previous one, except for the fact John/Ann performs a role of a client and the remaining participants are a "group translator" addressed by the client.

2. Outline of the main problem:

Problem communicated by the activity moderator to John/Ann: You are client who asked for a text translation into English. The translator accepted the job since they acknowledged that the text falls within their specialisation area. The deadline was accepted, and the rate was rewarding. The text was a research report. On completing the project, you complain about the wrong use of terminology: British concepts were used instead of American. 
Problem as reported by John/Ann to the group: I asked a translator to do a simple task of rendering my research report into English. They did ok, but did not care to use American terminology, using British variants instead.

3. Interview (example questions:)

- Do we know what happened on the basis of information provided by John/Ann?

- What kind of information is needed to have a broader picture of the case?

- What is the "problem" that John/Ann has? What are/can be its consequences?

- What about the translator in this case? Can you think of his view of the situation?

4. Framing

- How would you like to solve the problem being the client?

- How would you like to solve the problem being the translator?

- How to make both parties arrive at the agreed solution (for the future?)

\section{Brainstorming}

6. Feedback

In this scenario, it is particularly worthwhile to focus on avoiding student's statements of a kind "why did this translator not ask for details?" or "why did the client not suggest they want a particular terminology variant to be used." Instead of expressing blame, the participants will focus on how to develop briefing solutions for their own career to avoid simple, yet sometimes painful cases of miscommunication with clients.

\section{Scenario 3. Time management}

\section{AGENDA:}

1. The activity moderator (e.g. teacher) chooses one student to perform as John/Anne - the translator. The other students perform as solution designers. They cannot modify the main "problem storyline".

2. The moderator introduces a problem (story) to the student performing as John/Anne. The student can modify and add to the story. They can also consult (skilfully) the moderator on some details. It can be helpful if the student presents the outline of his story to the moderator before the activity is implemented.

Problem communicated by the activity moderator to John/Anne: When the client got in touch, you were happy to get the commission. You accepted the job after initial pre-analysis, even though the text was a hundred-page long and you did not feel relaxed after your last demanding assignment. You used your standard work time calculation. In the middle of the 
project it became clear you cannot work as long per day as you expected. What is more, internet connectivity was ruined for half of one day, which made everything even slower.

Problem reported by John/Anne to the group: I was happy to get a 100-page commission from a client. I pre-analysed the text and set the deadline, which the client accepted. It is true my last assignment turned out to be demanding and time consuming and I did not have enough time to relax after it. Now, when I am in the middle of the project, I am worried I cannot keep the deadline.

3. Interview

- What is the timeline of the event?

- What does the timeline tell you about John's/Anne's strategy of handling incoming assignments?

- What kind of time-management technique(s) are noticeable in John's/Anne's story

4. Framing

- What improvements of handling incoming assignments can be suggested?

- What improvements in time-management technique(s) can be designed?

\section{Brainstorming}

6. Feedback

\section{Scenario 4: Designing a translation agency}

\section{AGENDA:}

1. In this activity, students divided into groups work out their projects of a translation agency they would like to run (or work with). Dividing into groups may be random, but it may also use personal functioning style criteria (see e.g. the division into Analyticals, Drivers, Expressives and Amiables as outlined by Merrill and Reid 1999).

2. Groups work on the opening issues:

- What do I want to achieve with my agency in terms of business portfolio, size, types of clients and contracts?

- What is the distinctive competitive advantage of my agency (innovative branding).

- What do I want to achieve in my life? How is a translation agency helpful in that?

It is strongly recommended that the participants use present (I want to achieve...., I plan to do....) rather than future references, unless talking about the future discusses results of actions taken now (this will bring me to the point...). This communication technique makes thinking about the agency more realistic. 
3. These initial answers can now be operationalized into more business-related categories, e.g.:

- type of organization that matches our vision (a company, a network of freelancers...)

- portfolio that matches our vision (translation, translation and interpreting, transcreation, language consultancy...)

- development strategies (We focus on a limited number of strategic clients; we focus on wide client base; how do we handle cooperation with our entities and graduates?)

- quality management policy (What quality management would match our context best?)

- customer relations management and marketing policy (How to communicate our vision to the clients, what channels to use, with what purpose and expectations, how to realize our CSR policy)

- technological policy (What is the role of ICT in our business strategy for management, portfolio, quality and customer relations

- financial policy (initial capital, price policy, discounts etc.)

- formal (legal, fiscal etc) aspects of functioning

Working on these topics may be easier with visualisation, which is because these categories overlap and they represent related but distinct dimension of business functioning.

\section{Final presentation of designed agencies}

This stage of the activity needs to be well-structured or the activity moderator risks brining chaos to the classroom. Each presentation needs to be completed with a structured feedback session to inspire reflection.

As can be observed, this activity is scalable from a classroom exercise to a long-term project, depending on how realistic the design process is expected to be. If the activity moderator chooses a long-term approach, it is advisable to set the project in a virtual space (e.g. LMS) which can help students work out their ideas in an asynchronous mode. In fact, virtualization of the activity changes its dynamics into either blended or flipped type of learning interaction, which seems desirable for long-term projects.

\section{Conclusions}

This article was a recommendation for an educational use of Design Thinking as a tool encouraging creative problem solving, shared agency (collaboration) and effective communication. These skills and attitudes are vital for a classroom planned for a lifelong learning horizon, and teachers who subscribe to 
constructivist rather than instructionist educational approaches. This article contains only a brief outline of Design Thinking as a concept and the sketchy description of the Design Thinking working cycle. These are only an invitation for the reader to take up further research - and perhaps even more to undergo training - in the field of Design Thinking. To show the potential fields of application, and to inspire the reader's interest in the method, we provided proposals of two classroom activities that utilize part of the Design Thinking cycle. Our focus was on improving classroom communication on critical issues of the translation career that hardly make part of the formal curriculum of translation courses. The activities turn the classroom into a space of reflexive exploration of how to face professional challenges with creativity and team spirit. These activities can be modified in a few ways by the readers to match their educational contexts.

\section{References}

Brown, Tim. 2009. Change by Design. New York: Harper Collins.

EMT. 2009. Competences for Professional Translators, Experts in Multilingual and Multimedia Communication. Brussels: European Commission. [online] www.ec.europa.eu/dgs/translation/programmes/emt/key_documents/emt_competences_transla tors_en.pdf (accessed 28 May 2015)

EMT. 2017. European Master's in Translation. Competence Framework 2017. Brussels, European Commission [online] https://ec.europa.eu/info/sites/info/files/emt_competence_fwk_2017_en_web.pdf (accessed 10 May 2019)

Fernández Sánchez, Francesca. 2008. An example of a collaborative translation project incorporating mediation instruments as a means of encouraging self-regulation, in Garant, Mikel and Walker, Larry (eds.) Current Trends in Translation Teaching and Learning. Vol. II. Helsinki: University of Helsinki: 121-151.

González-Davies, Maria. 2004. Multiple Voices in the Translation Classroom: Activities, Tasks and Projects. Amsterdam and Philadelphia: John Benjamins.

Google. 2018. Guide: Practice Innovation with Design Thinking. [online] https://rework.withgoogle.com/guides/design-thinking/steps/introduction/ (accessed 31 December 2019)

Kiraly, Donald C. 2000. A Social Constructivist Approach to Translator Education. Empowerment from Theory to Practice. Manchester: St. Jerome Publishing.

Kiraly, Donald C. 2016. "Authentic project work and pedagogical epistemologies: A question of competing or complementary worldviews?" in Kiraly, Donald C. (ed.) Towards Authentic Experiential Learning in Translator Education. Mainz: Mainz University Press: 53-66.

Klimkowska, Katarzyna and Klimkowski, Konrad. 2015. Ksztattowanie kompetencji świadczenia ustug thumaczeniowych z perspektywy przysztych tlumaczy. Lublin: UMCS.

Klimkowski, Konrad. 2019a. "Assessment as a communicative activity in the translation classroom." InTRALinea. Special Issue: New Insights into Translator Training [online] http://www.intralinea.org/specials/article/2428 (accessed 31. December 2019)

Klimkowski, Konrad. 2019b. "Educational Theory: from Dewey to Vygotsky." in Laviosa, Sara and Gonzalez-Davies, Maria (eds.) The Routledge Handbook of Translation and Education. London: Routledge: 23-41. 
Klimkowski, Konrad. 2015. Towards a Shared Curriculum in Translator and Interpreter Education, Wrocław, Washington D.C.: WSF.

Massey, Gary and Brändli, Barbara. 2016. Collaborative feedback flows and how we can learn from them: Investigating a synergetic learning experience in translator education, in Kiraly, D.C. (ed) Towards Authentic Experiential Learning in Translator Education. Mainz: Mainz University Press. pp. 177-200.

Merrill, David M. and Reid, Robert H. 1999. Personal Styles and Effective Performance. New York: CRC Press.

Mourshed, Mona, Jigar Patel, Katrin Suder. 2014. Education to Employment: Getting Europe's Youth into Work. McKinsey and Company. [online] http://mckinseyonsociety.com/educationto-employment/report/ ED (accessed 28 October 2015)

Mourshed, Mona, Diana Farrell, Dominic Barton. 2012. Education to Employment: Designing a System that Works. McKinsey and Company. [online] http://mckinseyonsociety.com/educationto-employment/report/ (accessed 28 October 2015)

OECD. 2019. Education at a Glance 2019: OECD Indicators. Paris: OECD Publishing.

Pitkäsalo, Eliisa and Ketola, Anne. 2018. "Collaborative translation in a virtual classroom: Proposal for a course design." Transletters 1: 93-119.

Thelen, Marcel. 2019. "Quality and Quality Assessment in Translation: Paradigms in Perspective." in Huertas-Barros, Elsa, Vandepitte, Sonia, Iglesias-Fernandez, Emilia (eds.), Quality Assurance and Assessment Practices in Translation and Interpreting. Hershey PA: IGI Global: 1-25. 